Article

\title{
A Coordinated Dual-Channel Wide Area Damping Control Strategy for a Doubly-Fed Induction Generator Used for Suppressing Inter-Area Oscillation
}

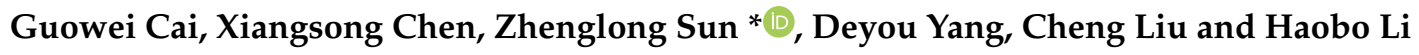

Key Laboratory of Modern Power System Simulation and Control \& Renewable Energy Technology, Ministry of Education (Northeast Electric Power University), Jilin 132012, China; cai4806439@126.com (G.C.); sevenchenpower@163.com (X.C.); dy0101232@163.com (D.Y.); 05dylc@163.com (C.L.); Tincky@126.com (H.L.)

* Correspondence: nedusunzl@neepu.edu.cn; Tel.: +86-138-4325-2382

Received: 15 April 2019; Accepted: 4 June 2019; Published: 8 June 2019

\begin{abstract}
Using a doubly-fed induction generator (DFIG), with an additional active or reactive damping controller, is a new method of suppressing the inter-area oscillation of a power system. However, using active power modulation (APM) may decrease the damping of the shaft oscillation mode of a DFIG and the system damping target cannot be achieved through reactive power modulation (RPM) in some cases. Either single APM or RPM does not consider system damping and torsional damping simultaneously. In this paper, an active-reactive coordinated dual-channel power modulation (DCPM) damping controller is proposed for DFIGs. First, considering the electromechanical parts and control structure of the wind turbine, an electromechanical transient model and an additional damping controller model of DFIGs are established. Then, the dynamic objective function for coordinating the parameters of the additional damping controller is proposed. The ratio between the active power channel and reactive power channel modulation is derived from the parameters optimized by the particle swarm optimization algorithm. Finally, the effectiveness and practicability of the designed strategy is verified by comparing it with a traditional, simple damping controller design strategy. Standard simulation system examples are used in the comparison. Results show that the DCPM is better at maximizing the damping control capability of the rotor-side controller of a DFIG and simultaneously minimizing adverse effects on torsional damping than the traditional strategy.
\end{abstract}

Keywords: low-frequency oscillation; damping control; torsional oscillation; doubly-fed induction generator; particle swarm optimization

\section{Introduction}

Wind power generation is the most developed renewable energy technology. Wind power has attracted considerable interest worldwide because it is clean and pollution free [1]. The most widely-used wind turbine technology is the doubly-fed induction generator (DFIG) [2]. The volatility and unpredictability of wind power and the high penetration of wind power to the power grid are among the factors contributing to low-frequency oscillation (LFO) in power systems. However, DFIG can be controlled flexibly and can affect system damping by disrupting the power flow or the coupling between generators and power systems to suppress LFO [3]. In some countries, guidelines on wind power grid stipulate that wind turbines should provide (or reserve) damping control functions are based on basic control. Therefore, improving the control strategy of the wind turbine and increasing its ability to suppress the power oscillation of a system are of great significance to the safe and stable operation of grids with high wind power penetration. 
A DFIG equipped with a power oscillating damper (POD) is suitable for handling power system oscillations [4]. On the one hand, it can increase damping performance when used in place of synchronous machines, which are equipped with power system stabilizers (PSSs) for the utilization of wind power. On the other hand, it increases the number of power system damping control points and expands the control range, thereby improving the damper electromechanical oscillation capability of a wind power system.

In recent years, DFIGs with additional damping controllers have been extensively researched. In [5], a traditional PSS in the synchronous machine in the control loop of the DFIG was used to suppress the low frequency oscillation of a power system. Initially, the input signal of the additional damping control of the DFIG is local. A wide-area measurement system (WAMS) enabled by the dispersed deployment of phasor measurement units (PMUs) can capture the dynamic information of a power system -i.e., voltage, current, angle, and frequency-at a high resolution and in near real-time. Owing to the development and advancement of the measurement system, a wide-area signal can be selected into the additional control and thus the damping characteristics of the DFIG can be further improved. It can be divided into active modulation and reactive modulation according to the type of DFIG output signal. In [5-7], an additional damping controller within the active power is proposed. The APM method can improve system damping by adjusting the rotor-side converter variable reference value. However, the damping of a DFIG-wind turbine shaft mode evidently decreases when APM is applied [8] and reduces the life and reliability of a drive shaft system. Given that DFIG can control active and reactive power independently, RPM through an additional control attached to the reactive power control circuit can damp power system oscillations [8-10]. This method does not increase the torque oscillation amplitude of a wind turbine drivetrain shaft. However, the effectiveness of RPM in suppressing inter-area oscillation depends on the reactive power injection position and voltage characteristics of the load. Therefore, in some cases, relying on RPM may not achieve the desired system damping [11].

A single active modulation cannot balance shaft torsional oscillation, and a single reactive modulation cannot match the desired system damping. In view of the modulation characteristics of the two additional damping controllers, a two-channel damping control strategy, which includes APM and RPM, is proposed in this paper, and the particle swarm optimization algorithm is used to optimize the controller parameters. This method allows the DFIG to maximize suppressing system oscillations and reduce the adverse effects on the shafting oscillation stability of the wind turbine.

This paper is organized as follows: First, the modeling of DFIG is described in Section 2. Next, the basic principle of additional damping control for DFIG and the control design are explained in Sections 3 and 4 . Subsequently, Section 5 provides the study results. Finally, the conclusion is given in Section 6.

\section{System Modeling}

The DFIG is a wound-rotor asynchronous generator with two voltage-source Pulse Width Modulation (PWM) converters. A schematic diagram of the DFIG wind turbine is shown in Figure 1. A wind turbine generator consists of a generator rotor, turbine shaft, gear box, and blades [12]. The turbine rotor is connected to the DFIG through a shaft system. The generator rotor is fed from the grid through a back-to-back converter which handles only the slip power. 


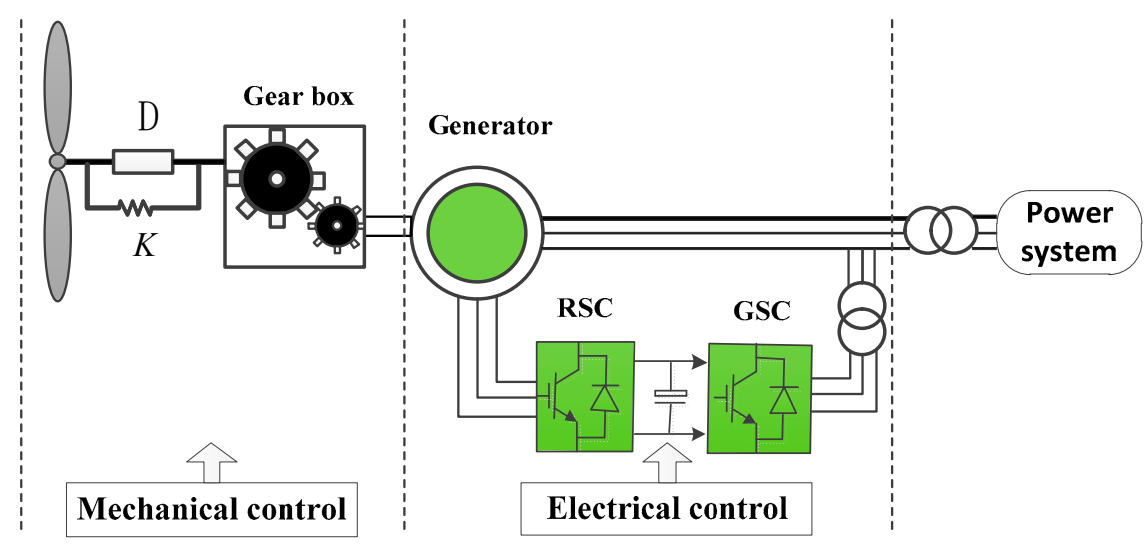

Figure 1. Doubly-fed induction generator (DFIG) wind turbine model and its control systems.

\subsection{Aerodynamic Model}

The torsional oscillation of the shafting was observed. Specifically, the transmission shaft adopts a two-mass model that considers the moment of inertia of the wind turbine and the doubly-fed generator. The aerodynamic model can be described as follows [13]:

$$
\begin{gathered}
T_{m}=\frac{0.5 \rho R^{2} C_{p}(\lambda, \beta) V_{\text {wind }}^{3}}{\omega_{W T}}, \\
C_{\mathrm{p}}(\lambda, \beta)=0.645\left(\frac{116}{\lambda_{i}}-0.4 \beta-5\right) e^{-21 / \lambda_{i}}, \\
\lambda_{i}=\frac{1}{1 /(\lambda+0.08 \beta)-0.035 /\left(\beta^{3}+1\right)}
\end{gathered}
$$

where $\rho, R, C_{p}, \lambda$, and $\beta$ are the air density, blade radius, power coefficient, tip speed ratio, and pith angle, respectively, $V_{\text {wind }}, T_{m}$, and $\omega_{W T}$ are the wind speed, mechanical torque, and wind turbine speed, respectively.

\subsection{Wind Turbine Torsional Dynamics Model}

The purpose of this study is to capture torsional dynamics. A two-mass model is sufficient in this case to investigate the torsional dynamics. This model is also widely used in several papers [14,15], when focusing on wind turbine mechanical dynamics. The equations of the two-mass model are listed as follows:

$$
\begin{gathered}
2 \frac{d \omega_{t}}{d t} H_{t}=T_{m}-T_{s}, \\
2 \frac{d \omega_{g}}{d t} H_{g}=T_{s}-T_{e}, \\
\frac{d \theta_{s}}{d_{t}}=\omega_{b}\left(\omega_{t}-\omega_{g}\right), \\
T_{s}=K \theta_{S}+D\left(\omega_{t}-\omega_{g}\right),
\end{gathered}
$$

where $\omega_{t}, \omega_{g}$, and $\omega_{b}$ are the generator speed, mechanical speed, and base mechanical speed, respectively. $\theta_{s}, T_{s}, T_{m}$, and $T_{e}$ are the shaft twist angle, shaft torque, mechanical torque, and electromagnetic torque, respectively. $D, K, H_{t}$, and $H_{g}$ are the damping factor, shaft spring constant, turbine inertia, and generator inertia, respectively. 


\subsection{DFIG Model}

Usually, the frequency of the oscillation modes with frequencies between 0.2 and $2.5 \mathrm{~Hz}$ in the system is lower than the grid frequency. Fast dynamics of the DFIG can be disregarded for the reduction of the model orders. The DFIG machine equations have been described in $[15,16]$. Then, the DFIG model can be presented by the following algebraic equation in the dq stationary reference frame:

$$
\begin{gathered}
\left\{\begin{array}{l}
\vec{u}_{s}=R_{s} \vec{i}_{s}+\dot{\psi}_{s}+j \vec{\psi}_{s} \omega_{s} \\
\vec{u}_{r}=R_{r} \vec{i}_{r}+\vec{\psi}_{r}+j \vec{\psi}_{r}\left(\omega_{s}-\omega_{g}\right)
\end{array}\right. \\
\left\{\begin{array}{l}
\vec{\psi}_{s}=L_{s} \vec{i}_{s}+L_{m} \vec{i}_{r} \\
\vec{\psi}_{r}=L_{r} \vec{i}_{r}+L_{m} \vec{i}_{s}
\end{array}\right. \\
T_{e}=\frac{3 n_{p}}{2} \operatorname{Re}\left(j \vec{\psi}_{s} \vec{i}_{s}\right)
\end{gathered}
$$

where $\vec{u}_{s}=u_{d s}+j u_{q s}, \vec{u}_{r}=u_{d r}+j u_{q r}$ are the stator and rotor voltage vectors; $\vec{i}_{s}=i_{d s}+j i_{q s}$ is the stator current vector; $\vec{i}_{r}=i_{d r}+j i_{q r}$ is the rotor current vector; $\vec{\psi}_{s}=\psi_{d s}+j \psi_{q s}$ is the stator flux vector; $\vec{\psi}_{r}=\psi_{d r}+j \psi_{q r}$ is the rotor flux vector; $L_{s}, L_{r}$, and $L_{m}$ are the stator, rotor, and magnetizing inductance, respectively; $R_{S}$ and $R_{r}$ are the stator and rotor resistance, respectively; $\omega_{s}$ is the grid frequency; and $n_{p}$ is the pole pair of the generator.

\section{Basic Principle of Additional Damping Control for DFIG}

The low-frequency oscillation of the power system is mainly caused by the unbalanced torque of the synchronous generator rotor. For inter-area power oscillations that occur between two clusters, the two clusters can be considered as equivalent two-machine systems for analyzing inter-area oscillations. This section will explain the principle of increasing the system damping of the DFIG according to the simple power system model shown in Figure 2. The two areas, each with a local load, are connected through a transmission line. The wind farm based on DFIG is integrated in area 1.

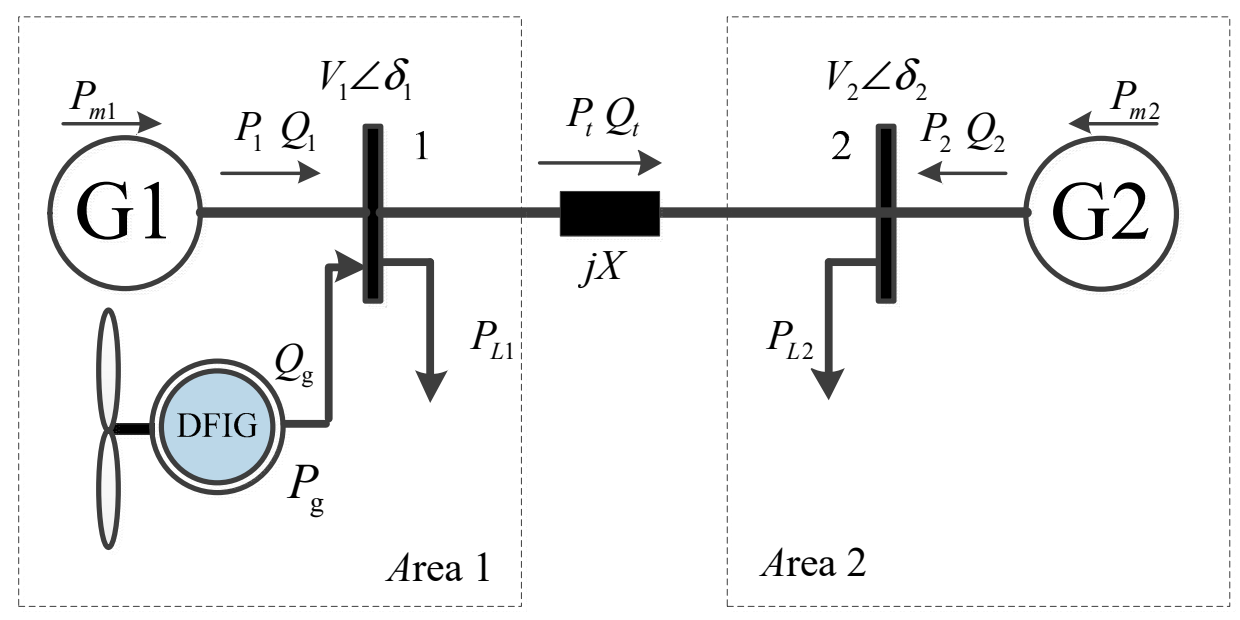

Figure 2. Simple power system model.

The dynamic model of the two-area power system without wind generation connection can be described with the swing equation in (11), which is widely used in [17]:

$$
\left\{\begin{array}{c}
\frac{d \delta_{12}}{d t}=\omega_{12} \\
\frac{d \omega_{12}}{d t}=\frac{1}{H_{1}}\left(P_{m 1}-P_{L 1}\right)-\frac{1}{H_{2}}\left(P_{m 2}-P_{L 2}\right)-\left(\frac{1}{H_{1}}+\frac{1}{H_{2}}\right) \frac{V_{1}}{V_{2}} \sin \delta_{12}
\end{array},\right.
$$


where $\omega$ is the generator rotor speed; $\delta$ is the generator rotor angle; $\delta_{13}=\delta_{1}-\delta_{3}$ and $\omega_{13}=\omega_{1}-\omega_{3}$ are the relative rotor angle and relative rotor speed, respectively, between the two areas; $H_{1}$ and $H_{2}$ are the equivalent inertia of areas 1 and 2, respectively; $P_{m 1}$ and $P_{m 2}$ are the mechanical power of generator 1 and generator 2, respectively; $X$ is the total impedance of the transmission line; and $V_{1}$ and $V_{2}$ are the voltages of Bus 1 and Bus 2, respectively. The damping coefficient of synchronous machine is not considered.

When the wind farm is linked to area 1, as illustrated in Figure 2, the system dynamic behavior can be described as [10]

$$
\left\{\begin{array}{c}
\frac{d \delta_{12}}{d t}=\omega_{12} \\
\frac{d \omega_{12}}{d t}=\frac{1}{H_{1}}\left(P_{m 1}+P_{w}-P_{L 1}\right)-\frac{1}{H_{2}}\left(P_{m 2}-P_{L 2}\right)-\left(\frac{1}{H_{1}}+\frac{1}{H_{2}}\right) \frac{V_{1}}{V_{2}} \sin \delta_{12}
\end{array},\right.
$$

where $P_{w}$ is the active power generated from the wind farm. As shown in Equation (12), by adding auxiliary power control to the DFIG, the DFIG can inject dynamic damping power into the system, thereby suppressing the electromechanical oscillation of the power system.

The low-frequency oscillation is also affected by the bus voltage, and the voltage amplitude is affected by the transmission of reactive power. The equation is related to (13). Power damping can be improved by modulating the bus voltage with reactive power control [18]:

$$
Q_{t}=Q_{g}+Q_{1}=\frac{V_{2}^{2}-V_{1} V_{2} \cos \delta_{12}}{X}
$$

where $Q_{t}, Q_{g}$, and $Q_{1}$ are the reactive power transmitted from area 1 to area 2, reactive power injection of DFIG, and the reactive power generated by synchronous generator 1, respectively. Bus voltage increases or decreases with the reactive power of the DFIG. The generator accelerates when voltage increases and decelerates when voltage decreases. The amplitude of oscillations can be reduced.

DFIG has two voltage-source PWM converters, i.e., a rotor side converter (RSC) and a grid side converter (GSC). The DFIG control includes RSC and GSC controllers for governing its active and reactive power. Figure 3 shows the block diagram of RSC controller.

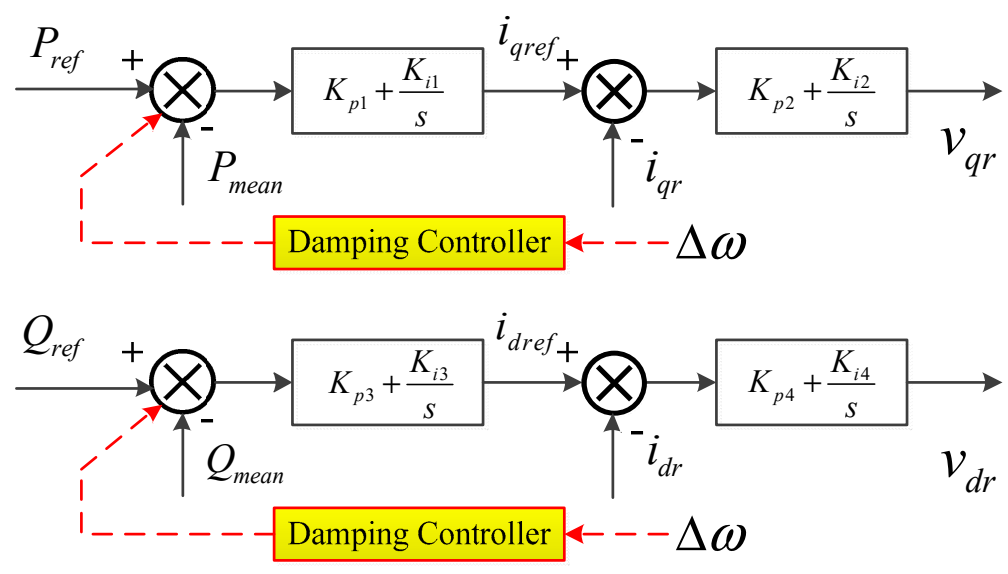

Figure 3. Control structure of the DFIG rotor-side converter.

The reactive power outer loop is cascaded with the q-axis rotor current inner loop, and the active power outer loop is cascaded with the d-axis rotor current inner loop. The q-axis loop is used to regulate the active power of DFIG $(\mathrm{P})$ and the axis loop is utilized to control the reactive power of DFIG stator $(\mathrm{Q})$. Active and reactive powers are regulated with the classical PI controllers.

Output is closely related to the d-axis and q-axis currents of the rotor due to the active and reactive power of the DFIG. The purpose of the rotor-side converter is to achieve effective control of 
the two-component current of the rotor and enable the independent decoupling of active and reactive power of the wind turbine.

Given the two existing separate controllers in RSC, additional functions can be carried out by supplementing the auxiliary controllers. The active and reactive power modulations will be achieved if the auxiliary controller is added to the active power or reactive power control loops, respectively.

\section{Optimal Tuning of Damping Controllers}

In the second and third sections, the appropriate DFIG system model is established, which lays the foundation for studying the grid-connected operation of wind turbines, and reflects the steady state and dynamic characteristics of DFIG as much as possible. In this section, the dual-channel damping controller parameters is tuned by the improved adaptive particle swarm optimization algorithm. The design method is described as follows.

\subsection{Controller Structure}

The excitation current of the DFIG is AC, and the output decoupling of active power and reactive power can be realized by changing the magnitude and phase of the excitation current.

The DFIG basically does not respond to the low-frequency oscillation of a power system. To involve the DFIG in suppressing the power system oscillation, the design of the additional damping controller should be based on the PSS of the synchronous generator. The specific additional damping control strategy using the conventional PSS control structure is shown in Figure 4. It consists of a stabilizer gain $K$, a washout filter with time constant, and two-phase compensator blocks with time constants $T_{1}$, $T_{2}, T_{3}$, and $T_{4}$. The selection of these control parameters will directly affect the working effect of the PSS. The additional signal forms a closed loop with the feedback signal and the additional damping signal is adjusted according to the system power oscillation, so that the DFIG increases the damping torque component and thereby suppresses the power oscillation.

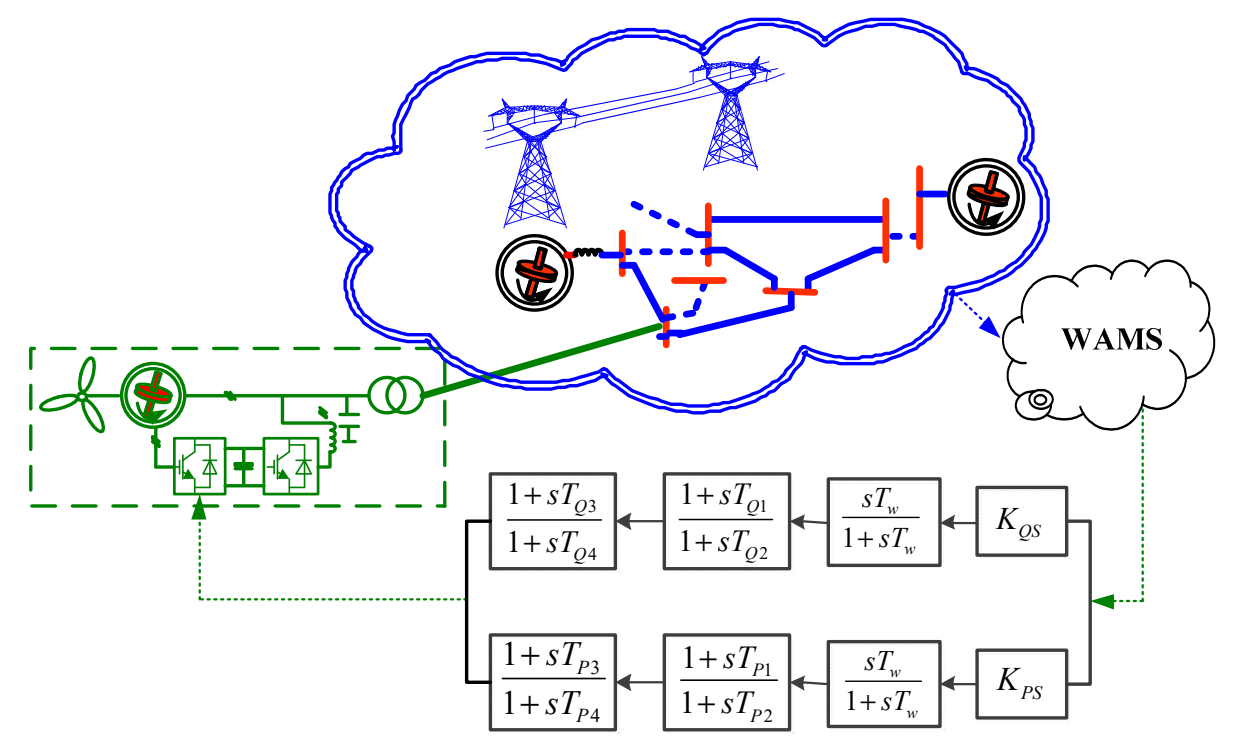

Figure 4. Block diagram of the dual-channel additional damping controller.

\subsection{Formulation of Optimization Problem}

For power system stability issues, the transition process time should be shorter, the oscillation amplitude should be small and disappear faster. In order to enhance system damping, the optimal constraints should be constructed for the purpose of rapid attenuation of the power-angle oscillation of the system generator after the fault and return to the steady state as soon as possible [19]. In the parameter optimization process, the main goal is to suppress power oscillation and maintain the 
overall stability of the system. Second, torsional oscillation should be taken into account to stabilize the dynamic characteristics of the DFIG in the objective function. The objective function can be expressed as:

$$
\mathrm{J}=\int_{0}^{t} \sum_{k=1}^{n} t\left[\left|\delta_{k}(t)-\delta_{k 0}\right|\right] d t+\alpha \int_{0}^{t} t\left|T_{e}(t)-T_{0}(t)\right| d t,
$$

where $t$ is the total simulation time, $\delta_{k}(t)$ is the rotor angle of the $k_{t h}$ generator in the inter-area oscillation mode operation, $\delta_{k 0}$ is the rotor angle of the $k_{t h}$ generator in the rated condition, $n$ is the number of generators, $T_{e}$ is the electromagnetic torque of the DFIG, $T_{0}$ is the electromagnetic torque steady state value, and $\alpha$ is the corresponding weight coefficient. In this paper, the value of $\alpha$ is 0.35 .

The objective is to minimize J such that it satisfies the following inequality constraints:

$$
\left\{\begin{array}{l}
K_{s}^{\text {min }} \leq K_{s} \leq K_{s}^{\max } \\
T_{1}^{\text {min }} \leq T_{1} \leq T_{1}^{\max } \\
T_{2}^{\min } \leq T_{2} \leq T_{2}^{\max } \\
T_{3}^{\min } \leq T_{3} \leq T_{3}^{\max } \\
T_{4}^{\min } \leq T_{4} \leq T_{4}^{\max }
\end{array}\right.
$$

Equation $K_{s}$ represents the gain of the damping signal (usually 1-50). Equations $T_{1}, T_{2}, T_{3}$, and $T_{4}$ are the time constant of the lead-lag block in the damping controller (usually 1-10 s). The designed controller needs to have the optimization parameter as follows:

$$
\mathrm{H}=\left[K_{Q}, K_{P}, T_{Q 1}, T_{Q 2}, T_{Q 3}, T_{Q 4}, T_{p 1}, T_{P 2}, T_{P 3}, T_{P 4}\right] .
$$

The dynamic performance of the system is ensured by finely tuning the DFIG controller parameters. The development of the particle swarm optimization algorithm is rapid owing to its comprehensibility, ease of implementation, and applicability in many fields. The time-varying inertia weighting factor is introduced into the particle swarm optimization algorithm (PSO), which enables the algorithm to effectively control the local search and provide sufficient convergence for the global optimal solution [20].

According to the principle of particle swarm optimization, the basic idea of additional damping parameter optimization is that a population of size $\mathrm{n}$ is formed first and then the particle is optimized according to the trend of the objective function. The particle variable can be continuously updated so that the objective function is continuously reduced until the convergence condition is satisfied. The basic steps of the optimization process are as follows:

(1) Modal analysis. The negative damping and weakly damped oscillation modes that threaten the system's safety and stability are determined through small interference analysis and the identification on the interconnected system.

(2) Feedback signal preselection. In the analysis system, the state variable that can be measured by the wide-area measurement system is observable for the main mode, and the state variable with a large residue is selected as the candidate signal. For interval oscillation, the best wide-area signal is the rotor angle difference [21,22]. In order to determine the controllability and observability of the interval oscillation mode, the optimal installation position of the damping controller using the residue method are the generator 4 and the wind farm [23].

(3) The initial values of the parameters, such as the speed, position, learning factor, and inertia constant of the population, are provided.

(4) According to the objective function, the individual optimal position and the global optimal target of the particle are automatically updated.

(5) Whether the number of loop iterations reaches the maximum value is determined. If the maximum number of iterations is not reached. The procedure returns to step 3 and continues to update the particle position and velocity; if the maximum number of iterations is reached, the optimal value of the fitness function and the position of each particle are determined. 


\section{Simulation Results and Discussion}

Time-domain simulations based on two-area four-machine system is conducted using the MATLAB/SIMULINK software to verify the analysis and effectiveness of the control scheme.

\subsection{Evaluation in Two-Area Four-Machine System}

The system diagram presented in Figure 5 is implemented in the simulation. The 2-area 4-machine system with wind farm is used to verify the control effect of the damping controller designed. Area 1 and area 2 have two synchronous generators each, and each generator produces $835 \mathrm{MW}$ rated power. The transmission power between the two areas is $408 \mathrm{MW}$. Only generator 4 is equipped with a PSS to increase the damping of its local oscillation. The parameters of the synchronous generators are shown in Table A1 of Appendix A. Wind farm based on DFIG is connected to the grid in area one and represented by one aggregated DFIG. The rated exporting level of the wind farm is $200 \mathrm{MW}$. The DFIGs operate in the maximum-power tracking active-control mode, and the reactive power adopts the unit power factor control mode. The specific parameters of the DFIG are shown in Table A2 of Appendix B.

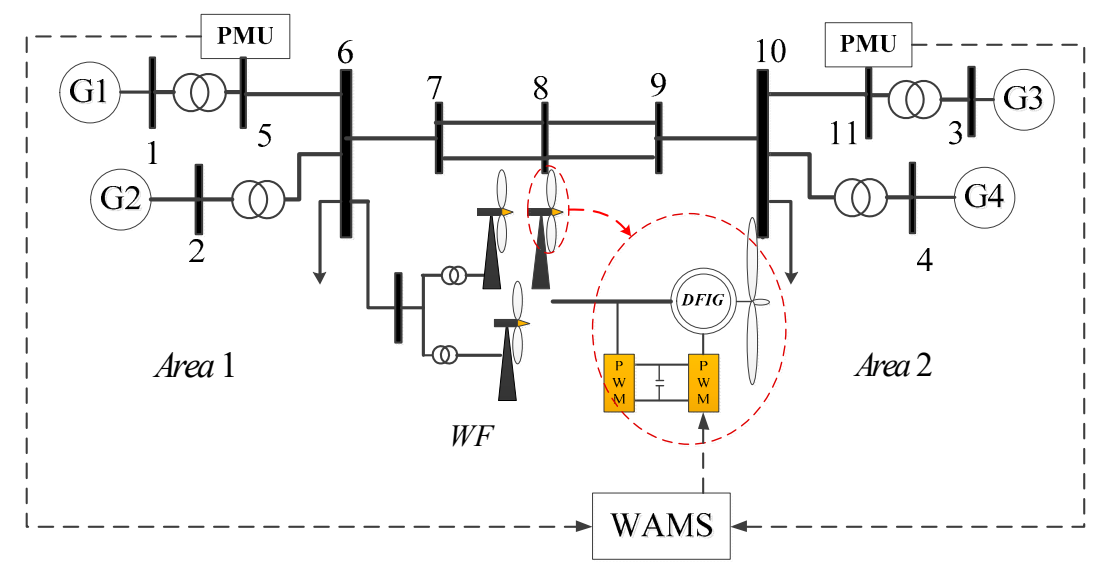

Figure 5. The simulation diagram of 2-area 4-machine system with DFIG wind farm.

\subsection{Parameter of Damping Controller}

The rotor angle between Generators 3 and $1\left(\delta_{13}\right)$ is selected as the controller input signal. The damping controllers are designed separately so that the LFO suppression effect of RPM, APM, and DCPM on the inter-area oscillation and its influence on the shafting oscillation of the doubly-fed wind turbine can be examined. The parameters of different modulation obtained by the PSO are shown in Table 1.

Table 1. Parameters of different modulation damping controller. DCPM: dual-channel power modulation; APM: active power modulation; RPM:

\begin{tabular}{ccccccc}
\hline Modulation Type & Channel & Gain & $\mathbf{T}_{\mathbf{1}}$ & $\mathbf{T}_{\mathbf{2}}$ & $\mathbf{T}_{\mathbf{3}}$ & $\mathbf{T}_{\mathbf{4}}$ \\
\hline DCPM & active & 10.2 & 0.079 & 0.22 & 0.081 & 0.21 \\
APM & reactive & 48.3 & 0.081 & 0.21 & 0 & 0 \\
RPM & active & 50 & 0.078 & 0.21 & 0.081 & 0.21 \\
& reactive & 50 & 0.081 & 0.21 & 0 & 0 \\
\hline
\end{tabular}

\subsection{Simulations and Analysis Under Different Circumstances}

For the full testing of the effectiveness of the proposed adaptive wide-area damping control scheme, the following two representative disturbances are considered:

Case A: large disturbance-at t of $10 \mathrm{~s}$, a three-phase short-circuit fault occurs at Bus 7, and the fault is removed at $10.1 \mathrm{~s}$. 
Case B: small disturbance- the active power load at Bus 6 is increased by $20 \%$ at $\mathrm{t}$ of $10 \mathrm{~s}$ and then restored back to the original value at $\mathrm{t}$ of $11 \mathrm{~s}$.

The system has several oscillation modes: (1) local electromechanical oscillations $(1.2 \mathrm{~Hz})$ due to one synchronous machine swinging against a local area; (2) the inter-area mode $(0.65 \mathrm{~Hz})$ due to Area 1 swinging against Area 2; and (3) the wind turbine shaft mode $(1.82 \mathrm{~Hz})$.

\subsubsection{Compare APM and RPM}

Figure 6 shows a dynamic response diagram of the transmission power of the Line 7-9 under APM and RPM. As shown in Figure 6, without an additional damping controller, the amplitude of power oscillation of the transmission line is larger than that with an additional controller. Figure 7 shows a dynamic response diagram of the rotor speed of Generator 3 under APM and RPM. Through simulation comparison, it is found that the damping capacity provided by APM is stronger than that of RPM. Oscillation attenuation speed is faster and the transient oscillation amplitude is smaller under the active modulation. The active power modulation has good control performance when the power system appears inter-area oscillations, thereby verifying the control effect.

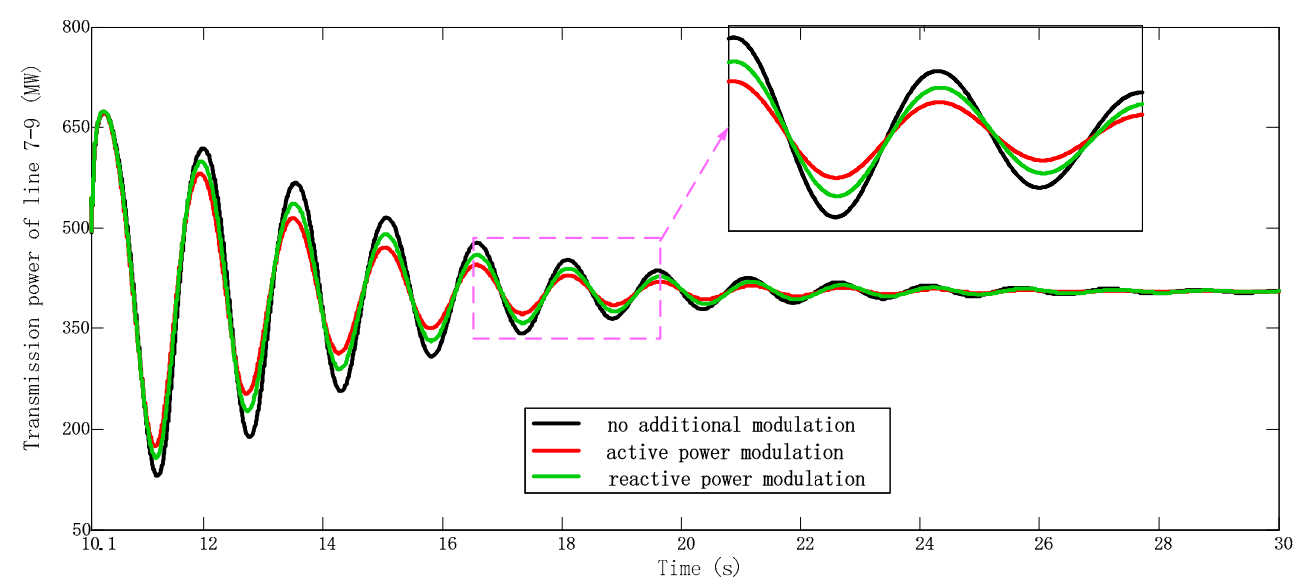

(a)

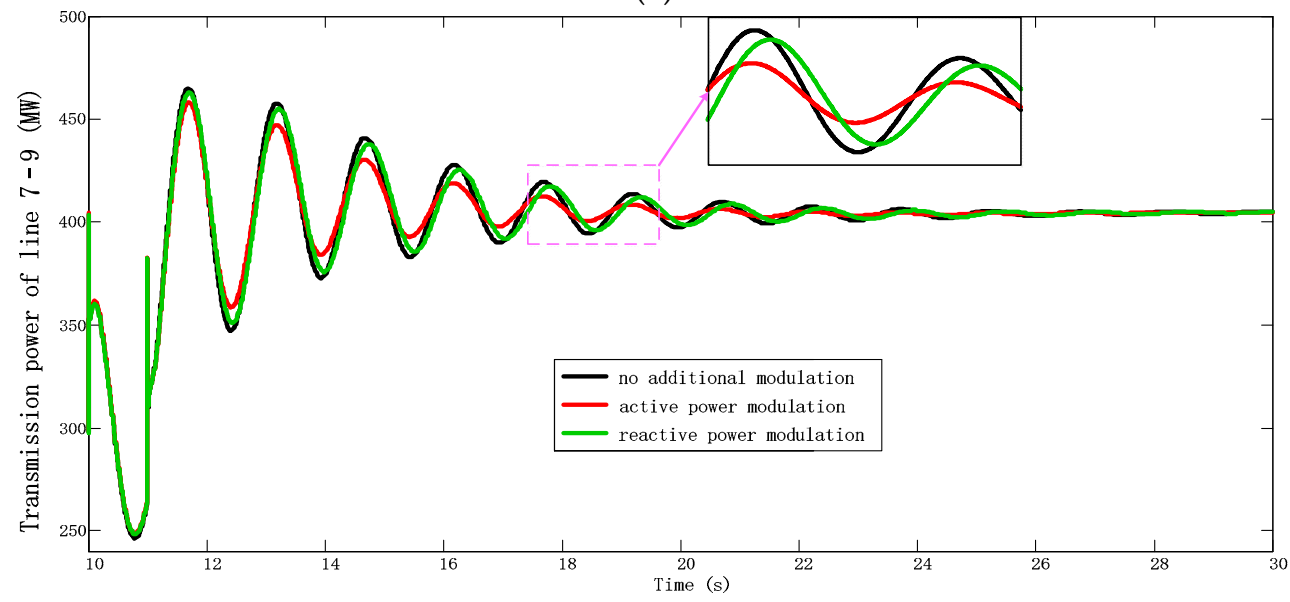

(b)

Figure 6. (a) Transmission power of Line 7-9 at Case A; (b) Transmission power of Line 7-9 at Case B. 


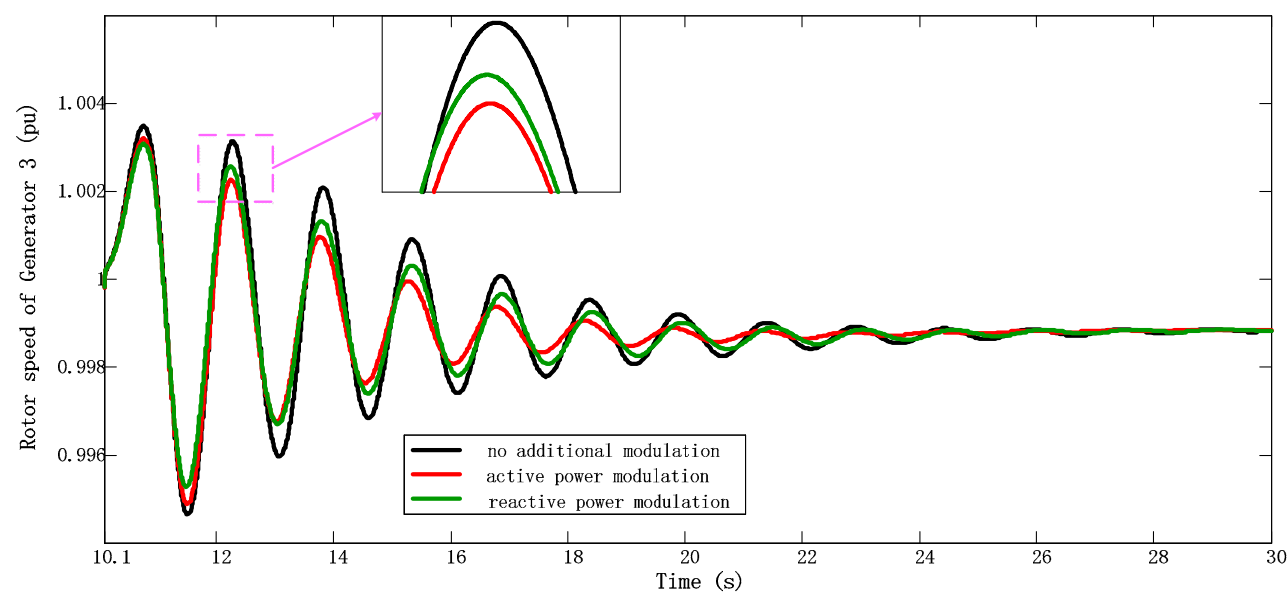

(a)

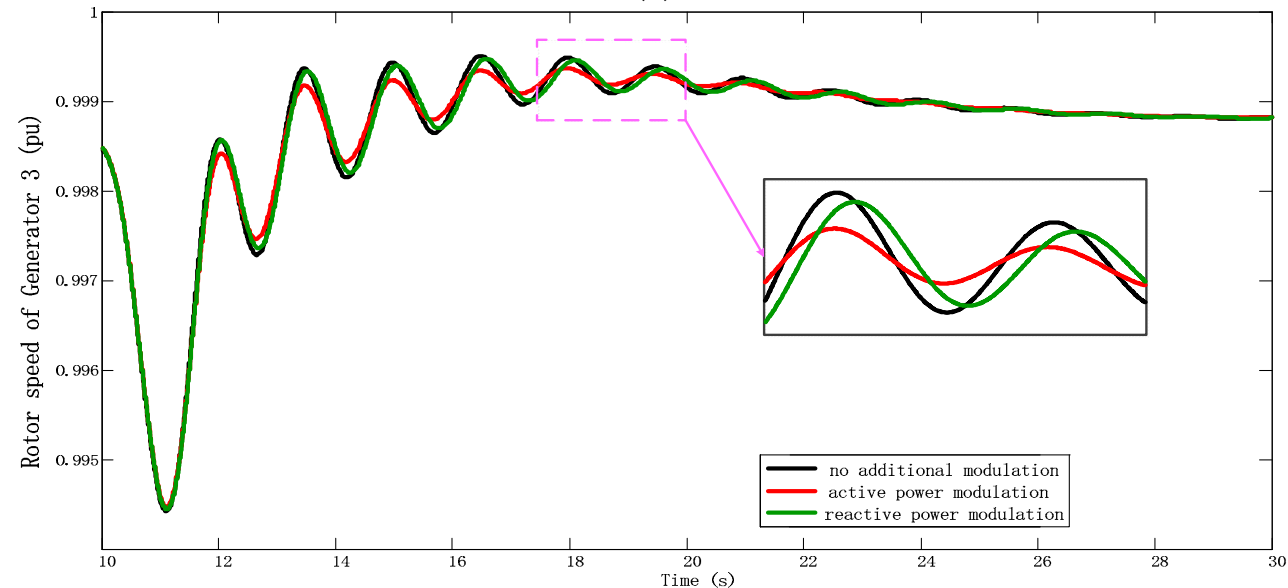

(b)

Figure 7. (a) Rotor speed of Generator 3 at Case A; (b) Rotor speed of Generator 3 at Case B.

\subsubsection{Compare APM and DCPM}

Figures 8 and 9 show a dynamic response diagram of the transmission power of Line 7-9 and the rotor speed of Generator 3 under APM and DCPM. It can be seen that the damping capacity provided by the dual-channel power modulation is nearly the same as the active modulation; the oscillation attenuation speed is fast, and the transient oscillation amplitude is small.

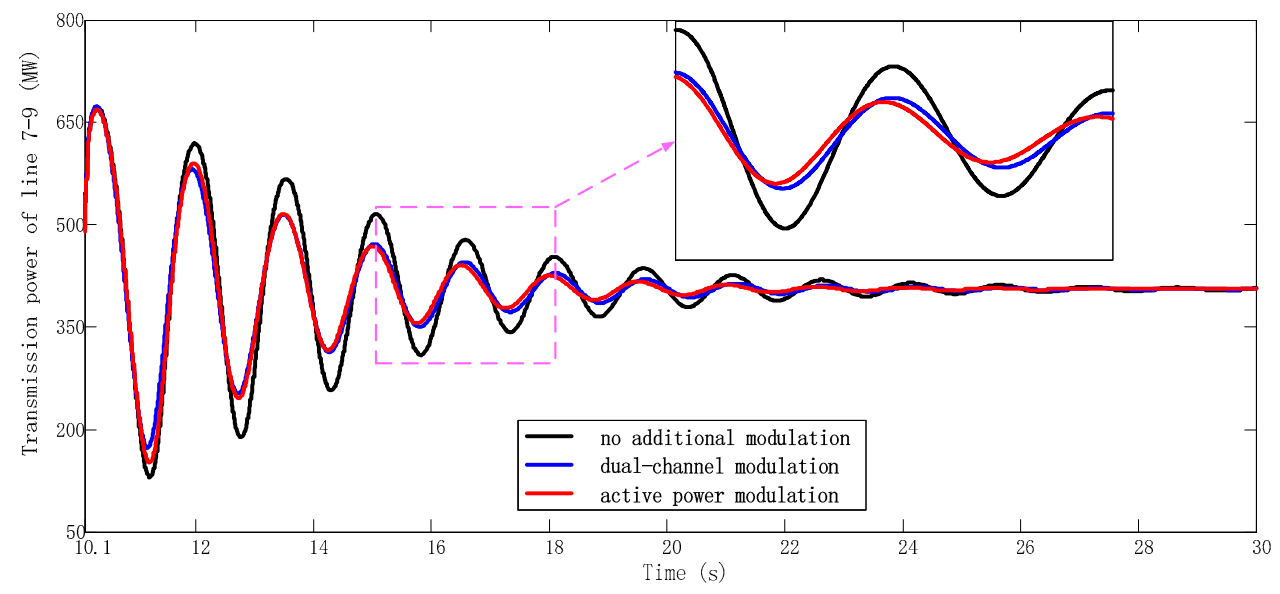

(a)

Figure 8. Cont. 


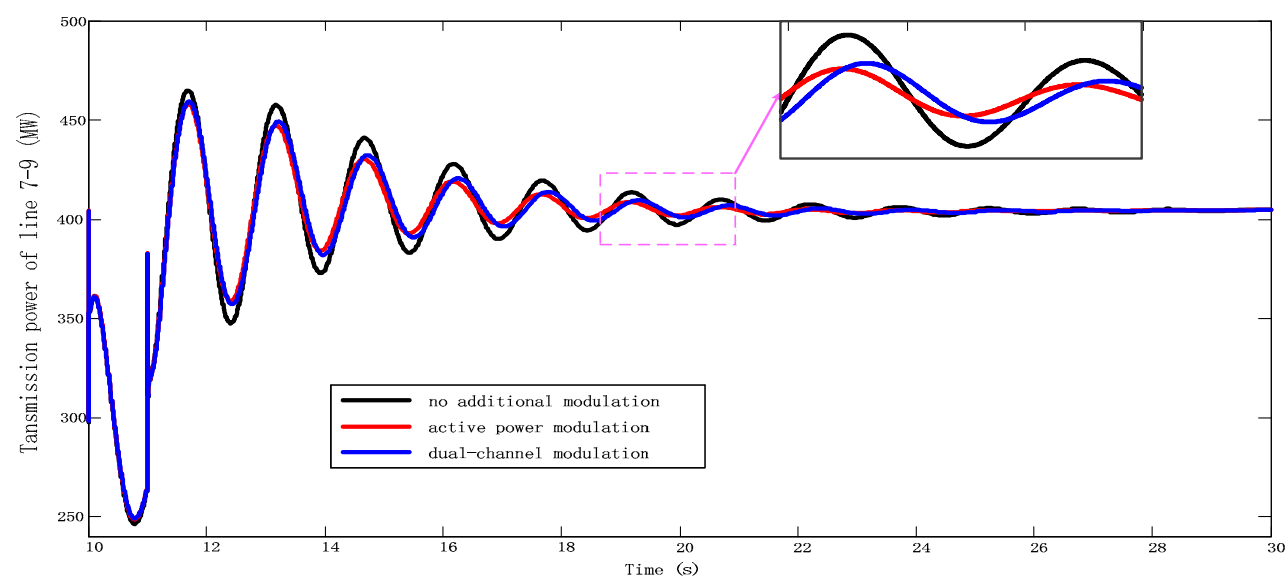

(b)

Figure 8. (a) Transmission power of Line 7-9 at Case A; (b) Transmission power of Line 7-9 at Case B.

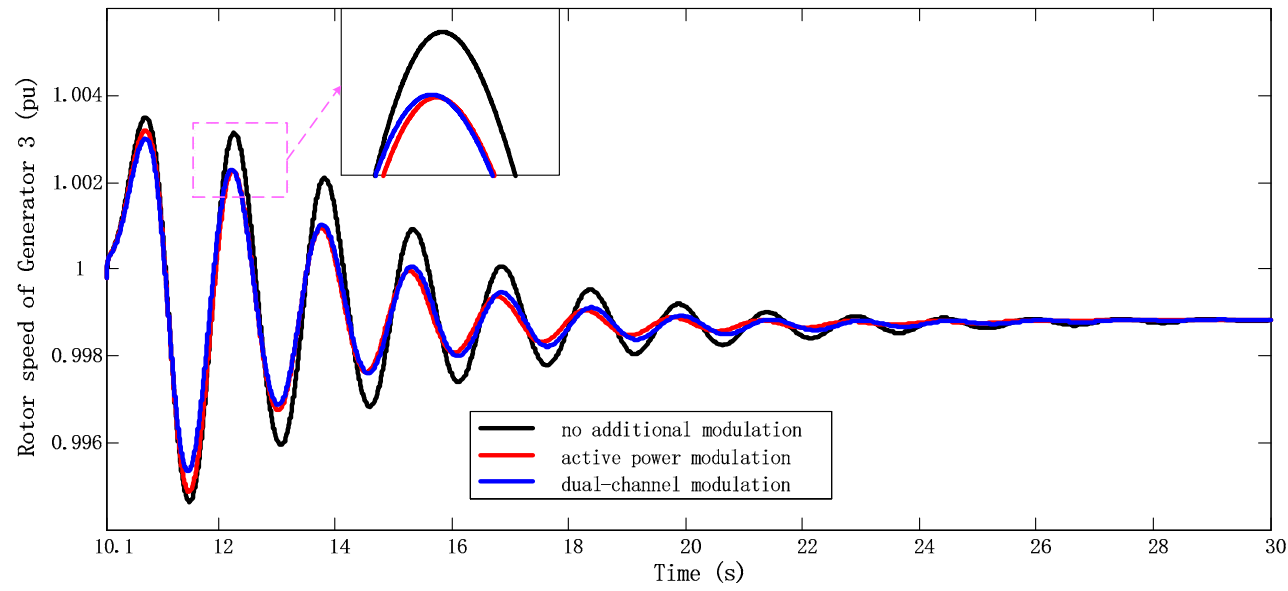

(a)

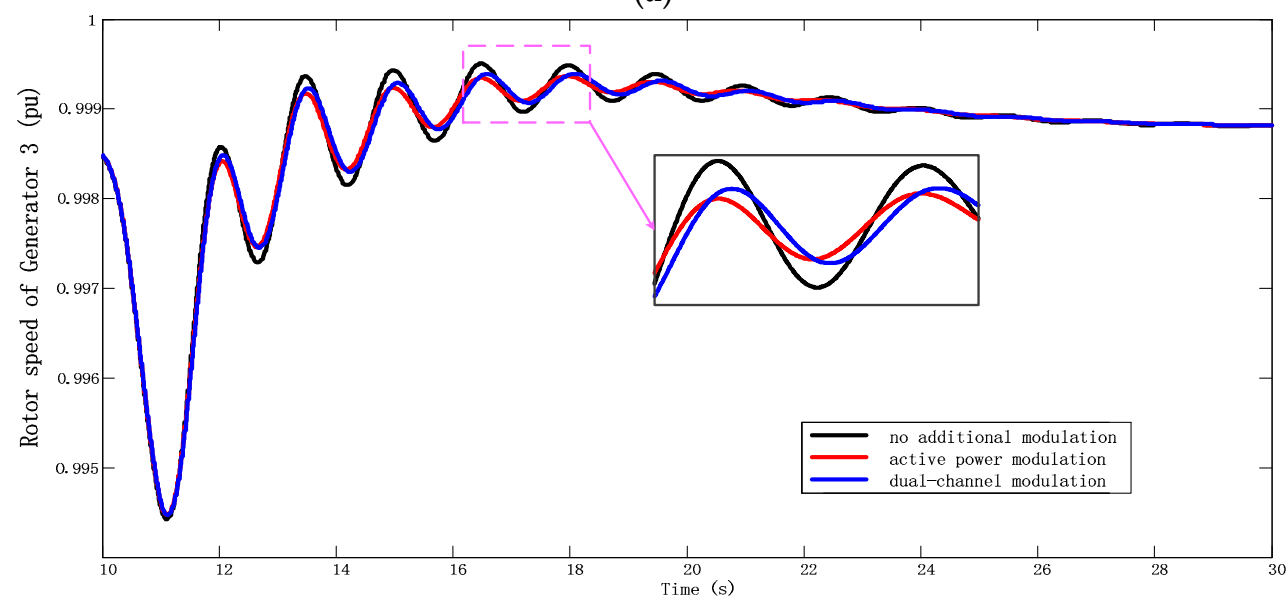

(b)

Figure 9. (a) Rotor speed of Generator 3 at Case A; (b) Rotor speed of Generator 3 at Case B.

\subsubsection{Compare RPM and DCPM}

Figures 10 and 11 show a dynamic response diagram of the transmission power of Line 7-9 and the rotor speed of Generator 3 under RPM and DCPM. The single RPM provides a weaker damping capability. Under the action of the dual-channel power modulation, the oscillation amplitude and the attenuation time are reduced, and the control performance is verified. 


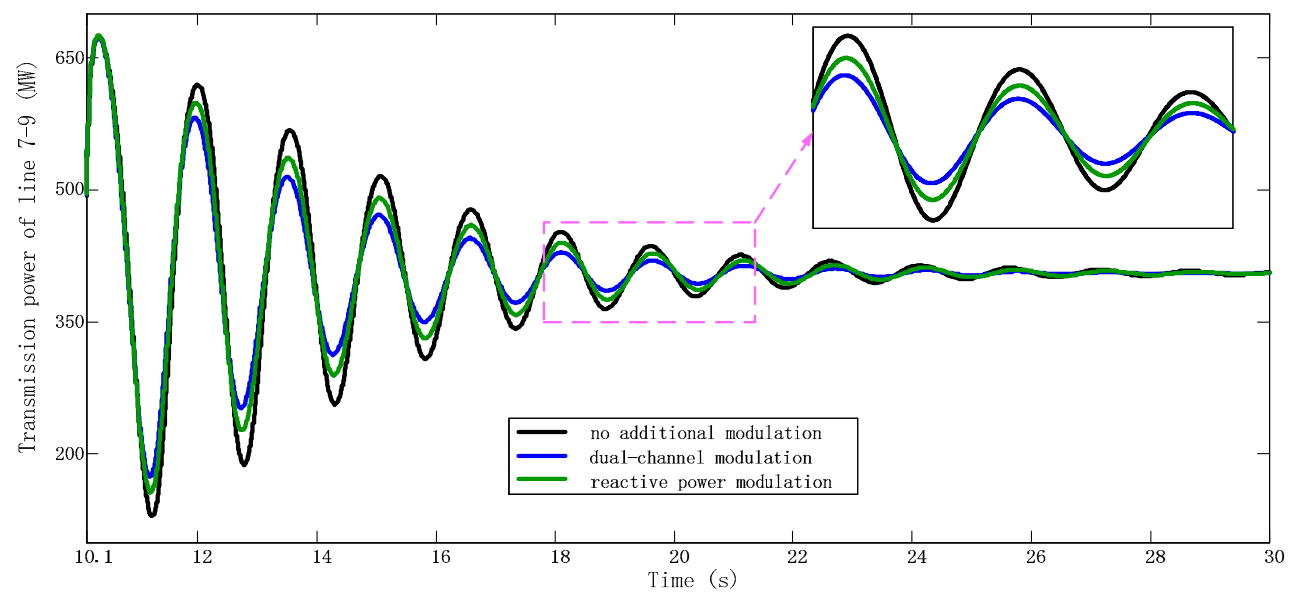

(a)

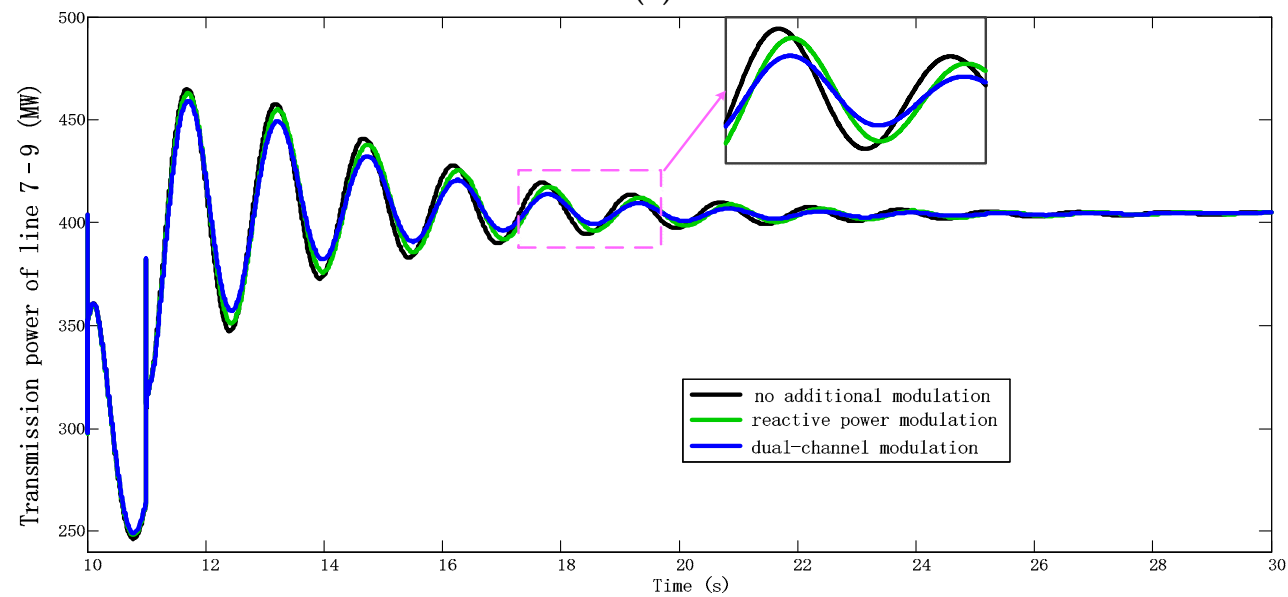

(b)

Figure 10. (a) Transmission power of Line 7-9 at Case A; (b) Transmission power of Line 7-9 at Case B.

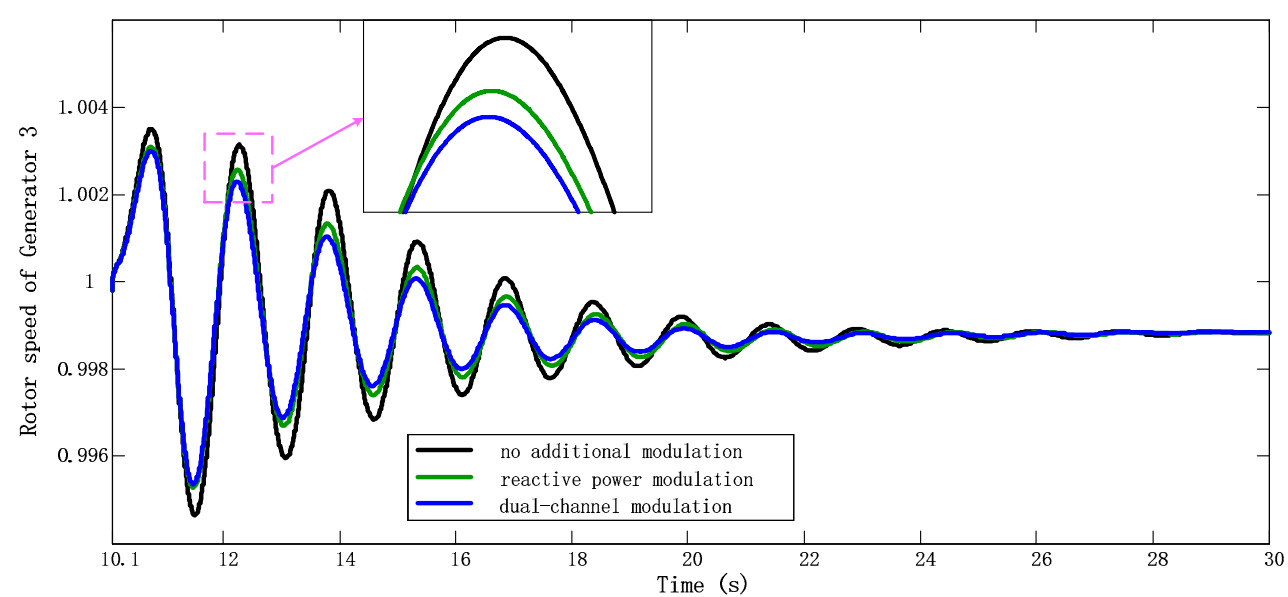

(a)

Figure 11. Cont. 


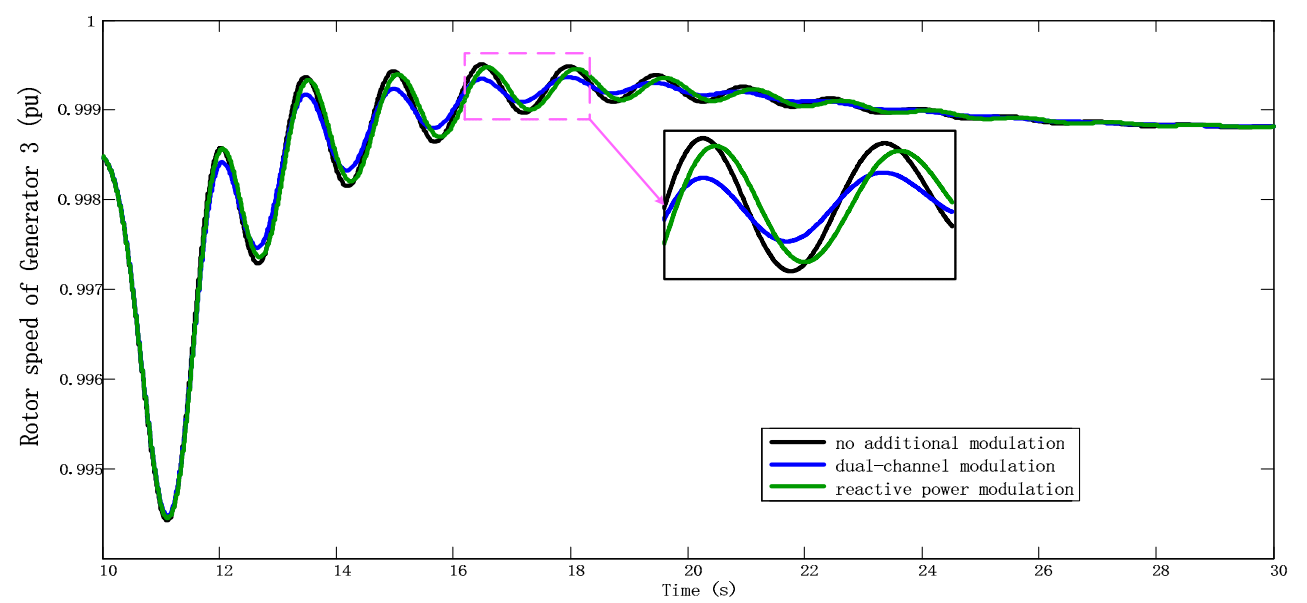

(b)

Figure 11. (a) Rotor speed of Generator 3 at Case A; (b) Rotor speed of Generator 3 at Case B.

\subsubsection{DFIG's Shaft Dynamic after Additional Control}

The above comparison shows that the active power additional damping control has a better suppression effect on inter-area oscillation of a system. As the additional active damping controller increases the damping signal gain, the suppression effect is pronounced. As the gain of the damping signal increases, the unbalanced torque excites the torsional oscillation mode of the shafting, and the amplitude of the torsional oscillation of the wind turbine increases. The amplitude of the inherent torsional oscillation frequency of the DFIG's shaft system is increased to an extent.

Figure 12 shows the dynamic response of the shaft torque of the DFIG. An inherent wind turbine shaft oscillation mode exists in the DFIG. Evidently, the active power modulation exacerbates the amplitude of the oscillations. Figure 13 shows the dynamic response of the electromagnetic torque of the DFIG. As shown in Figure 13, the fluctuation of the torsional oscillation affects the electromagnetic torque fluctuation through the shafting, which in turn causes the fluctuation of the active output amplitude of the DFIG to increase. The active power output of DFIG is plotted in Figure 14. When the output power of the doubly-fed wind turbine is injected into the power grid, an oscillation component of about $1.82 \mathrm{~Hz}$ appears in the output power of the wind farm because of the unstable shaft speed oscillation. As the penetration rate of wind energy continues to increase, the fluctuation of the active output of the wind turbine adversely interacts with the power system and threatens the stability of the power system.

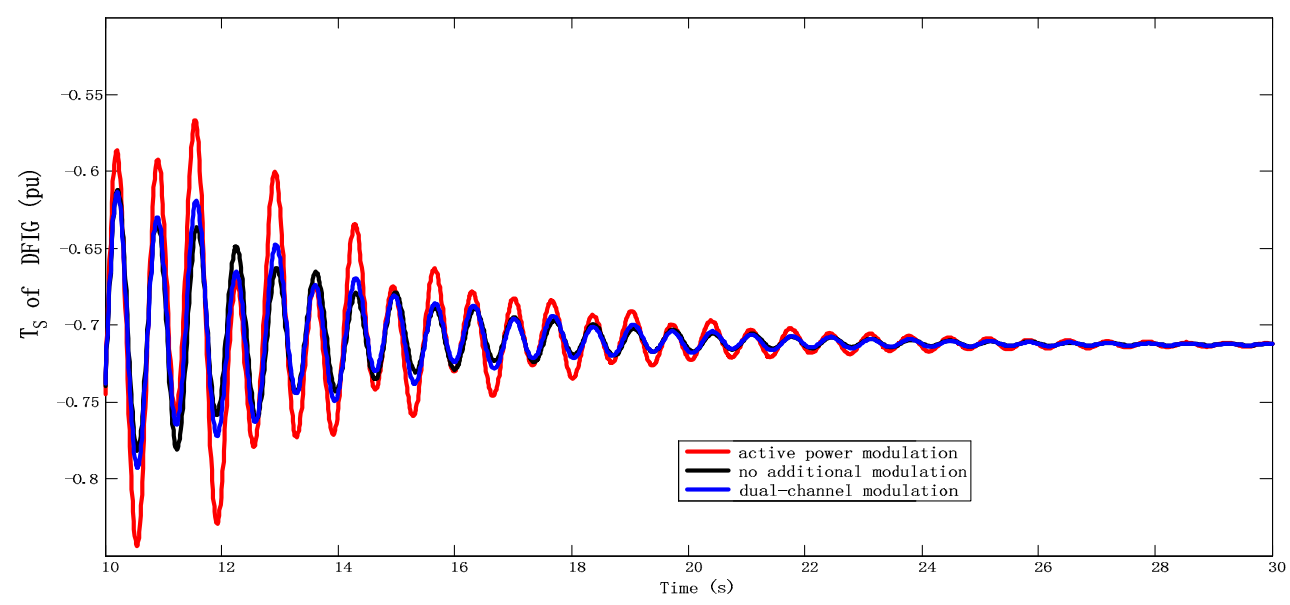

Figure 12. $T_{S}$ of DFIG at Case A. 


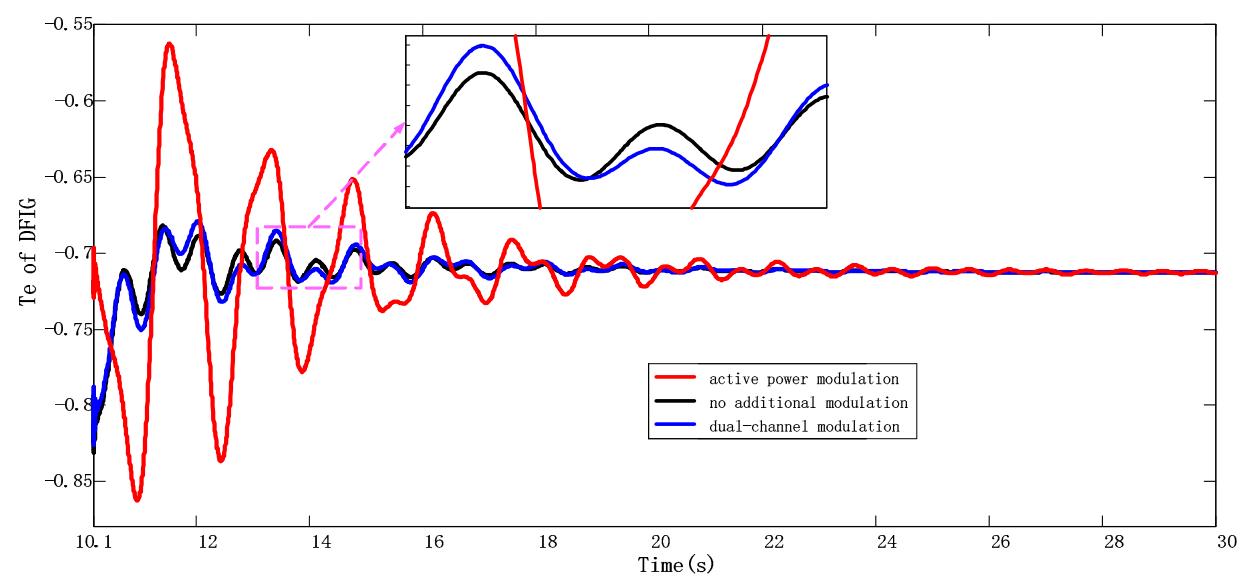

Figure 13. $T_{e}$ of DFIG at Case A.

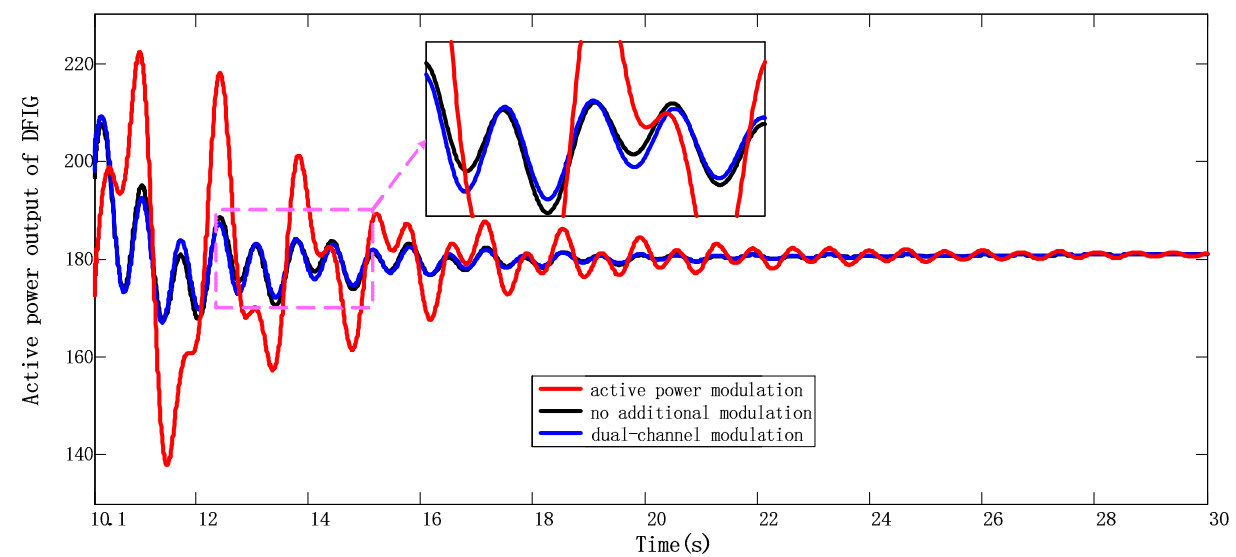

Figure 14. Active power output of DFIG at Case A.

The design of DCPM can flexibly and feasibly allocate the damping control burden between active and reactive power channels of DFIG. The results show that the dual-channel additional damping control can better balance the fluctuations of the shafting torque and also has a good performance in suppressing the inter-area oscillation.

The test system shown in Figure 5 has a higher order and analytical mathematical modeling is challenging. This paper uses MATLAB's Prony Toolbox to solve the system eigenvalues, including the wind turbine torsional mode, to confirm the above analysis. The damping of the inter-area oscillation mode and the torsional oscillation mode under different operating states according to the eigenvalue analysis is shown in Table 2.

Table 2. Inter-area damping and torsional damping under various operating states and modulation methods.

\begin{tabular}{ccccc}
\hline Control Mode. & $\begin{array}{c}\text { Inter-area Oscillation } \\
\text { Frequency/Hz }\end{array}$ & Damping (\%) & $\begin{array}{c}\text { Shaft Oscillation } \\
\text { Frequency/Hz }\end{array}$ & Damping (\%) \\
\hline No & 0.65 & 1.21 & 1.82 & 7.21 \\
DCPM & 0.65 & 8.05 & 1.82 & 6.52 \\
APM & 0.64 & 8.11 & 1.82 & 4.13 \\
RCM & 0.65 & 5.21 & 1.82 & 7.23 \\
\hline
\end{tabular}

As shown in the above table, the hybrid dual-channel modulation has better ability to suppress electromechanical oscillation than the reactive modulation. Compared with the active additional modulation, in the case of similar suppression of electromechanical oscillation capability, the torsional dynamic of the shaft can be considered, and it can simultaneously minimize the adverse effects on torsional damping 


\section{Conclusions}

A method for damping inter-area oscillations using a dual-channel modulation controller of DFIG is proposed. The DFIG active-reactive power additional damping controller is obtained by using the improved adaptive particle swarm optimization algorithm. The control effect of the proposed damping controller is verified through the transient simulation of the 2-area 4-machine system with wind farm. The number of oscillations in the torque increases when active power modulation is applied and reaching the damping target when reactive power modulation is applied is difficult. The DCPM controller performs well in suppressing low frequency oscillation and minimizes the adverse effects on torsional damping. The design can better balance DFIG's dynamics and damping low frequency oscillation. It avoids the harmful interaction of the shaft torsional oscillation on the power system and is conducive to the stable operation of the system. Lastly, it can provide effective reference and help for the suppression of low frequency oscillation grid-connected wind turbines. The damping control strategy in this paper is only suitable for offline application, our future work will focus on the online regulation.

Author Contributions: X.C. and Z.S. conceived and designed the study. X.C. and H.L. performed the experiments. X.C. and Z.S. wrote the paper. G.C., D.Y. and C.L. reviewed and edited the manuscript. All authors read and approved the manuscript.

Funding: This work was funded by National Key Research and Development Programme (2016YFB0900100), State Grid Corporation of China (SGJLDK00KJJS1800061), and Jilin Province Outstanding Young Talents Foundation Project of China (20180520067JH).

Conflicts of Interest: The authors declare no conflict of interest.

\section{Appendix A}

Table A1. Parameters of the synchronous generator.

\begin{tabular}{cccc}
\hline$r_{s}$ & $0.003(\mathrm{pu})$ & $X_{l s}$ & $0.19(\mathrm{pu})$ \\
$X_{q}$ & $1.8(\mathrm{pu})$ & $X_{d}$ & $1.8(\mathrm{pu})$ \\
$r_{k q 1}^{\prime}$ & $0.00178(\mathrm{pu})$ & $r_{f d}^{\prime}$ & $0.00093(\mathrm{pu})$ \\
$X_{l q 1}^{\prime}$ & $0.8125(\mathrm{pu})$ & $X_{l f d}^{\prime}$ & $0.11414(\mathrm{pu})$ \\
$r_{k q 2}^{\prime}$ & $0.00841(\mathrm{pu})$ & $r_{k d}^{\prime}$ & $0.01334(\mathrm{pu})$ \\
$X_{l q 2}^{\prime}$ & $0.0939(\mathrm{pu})$ & $X_{l k d}^{\prime}$ & $0.08125(\mathrm{pu})$ \\
\hline
\end{tabular}

\section{Appendix B}

Table A2. Parameters of the DFIG.

\begin{tabular}{cc}
\hline$S_{\text {Nom }}$ & $1.67 \mathrm{MVA}$ \\
$V_{\text {Nom }}$ & $575 \mathrm{~V}$ \\
$R_{S}$ & $0.0071(\mathrm{pu})$ \\
$R_{r}$ & $0.005(\mathrm{pu})$ \\
$L_{l s}$ & $0.1714(\mathrm{pu})$ \\
$L_{l r}$ & $0.1563(\mathrm{pu})$ \\
$L_{m}$ & $2.903(\mathrm{pu})$ \\
$\mathrm{K}$ & $1.11(\mathrm{pu})$ \\
$\mathrm{D}$ & $0.65(\mathrm{pu})$ \\
$H_{g}$ & $0.62 \mathrm{~s}$ \\
$H_{t}$ & $4.33 \mathrm{~s}$ \\
\hline
\end{tabular}

\section{References}

1. Islam, M.R.; Guo, Y.; Zhu, J. A review of offshore wind turbine nacelle: Technical challenges, and research and developmental trends. Renew. Sustain. Energy Rev. 2014, 33, 161-176. [CrossRef] 
2. Muller, S.; Deicke, M.; De Doncker, R.W. Doubly fed induction generator systems for wind turbines. IEEE Ind. Appl. Mag. 2002, 8, 26-33. [CrossRef]

3. Yanfeng, M.; Jia, L.; Haihang, L. Active-Reactive Additional Damping Control of a Doubly-Fed Induction Generator Based on Active Disturbance Rejection Control. Energies 2018, 11, 1314-1331.

4. Domínguez-García, J.L.; Gomis-Bellmunt, O.; Bianchi, F.D. Power oscillation damping supported by wind power: A review. Renew. Sustain. Energy Rev. 2012, 16, 4994-5006. [CrossRef]

5. Hughes, F.M.; Anaya-Lara, O.; Jenkins, N. A power system stabilizer for DFIG-based wind generation. IEEE Trans. Power Syst. 2006, 21, 763-772. [CrossRef]

6. Miao, Z.; Fan, L.; Osborn, D. Control of DFIG-Based Wind Generation to Improve Interarea Oscillation Damping. IEEE Trans. Energy Convers. 2009, 24, 415-422. [CrossRef]

7. Tan, A.; Lin, X.; Sun, J. A Novel DFIG Damping Control for Power System with High Wind Power Penetration. Energies 2016, 9, 521. [CrossRef]

8. Fan, L.; Yin, H.; Miao, Z. On Active/Reactive Power Modulation of DFIG-Based Wind Generation for Interarea Oscillation Damping. IEEE Trans. Energy Convers. 2011, 26, 513-521.

9. Tsourakis, G.; Nomikos, B.M.; Vournas, C.D. Contribution of Doubly Fed Wind Generators to Oscillation Damping. IEEE Trans. Energy Convers. 2009, 24, 783-791. [CrossRef]

10. Liao, K.; He, Z.; Xu, Y. A Sliding Mode Based Damping Control of DFIG for Interarea Power Oscillations. IEEE Trans. Sustain. Energy 2016, 8, 258-267. [CrossRef]

11. Kundur, P. Power System Stability and Control, 1st ed.; McGraw-Hill: New York, NY, USA, 1994; pp. 1128-1160.

12. Mokhtari, M.; Aminifar, F. Toward Wide-Area Oscillation Control Through Doubly-Fed Induction Generator Wind Farms. IEEE Trans. Power Syst. 2014, 29, 2985-2992. [CrossRef]

13. Xi, X.; Geng, H.; Yang, G. Modelling of the DFIG Based Wind Farms for Small Signal Stability Analysis of Weak Power Grids. In Proceedings of the Renewable Power Generation Conference IET, Beijing, China, 9-11 September 2013.

14. Li, H.; Chen, H.; Yang, C. Ancillary damping control strategy for wind farms with doubly-fed induction generators using power signals in transmission lines. Autom. Electr. Power Syst. 2012, 36, $28-33$.

15. Geng, H.; Xi, X.; Liu, L. Hybrid Modulated Active Damping Control for DFIG based Wind Farm Participating in Frequency Response. IEEE Trans. Energy Convers. 2017, 32, 1220-1230. [CrossRef]

16. Lei, T.; Barnes, M.; Ozakturk, M. Doubly-fed induction generator wind turbine modelling for detailed electromagnetic system studies. IET Renew. Power Gener. 2013, 7, 180-189. [CrossRef]

17. Liao, K.; Xu, Y.; Wang, Y. Hybrid fast damping control strategy for doubly fed induction generators against power system inter-area oscillations. IET Renew. Power Gener. 2018, 12, 463-471. [CrossRef]

18. Nguyen-Duc, H.; Dessaint, L.; Okou, A.F. A Power Oscillation Damping Control Scheme Based on Bang-Bang Modulation of FACTS Signals. IEEE Trans. Power Syst. 2010, 25, 1918-1927. [CrossRef]

19. Sunkara, S.K.; Narne, R.; Panda, P.C. Coordinated Tuning of PSS with TCSC Damping Controller Through Advanced Adaptive PSO for a Multi-Machine Power System. In Proceedings of the 2013 International Conference on Energy Efficient Technologies for Sustainability, Nagercoil, India, 10-12 April 2013.

20. Ratnaweera, A.; Halgamuge, S.K.; Watson, H.C. Self-Organizing Hierarchical Particle Swarm Optimizer with Time-Varying Acceleration Coefficients. IEEE Trans. Evolut. Comput. 2004, 8, 240-255. [CrossRef]

21. Fan, L.; Feliachi, A.; Schoder, K. Selection and design of a TCSC control signal in damping power system inter-area oscillations for multiple operating conditions. Electr. Power Syst. Res. 2002, 62, 127-137. [CrossRef]

22. Larsen, E.V.; Sanchezgasca, J.J.; Chow, J.H. Concepts for design of facts controllers to damp power swings. IEEE Trans. Power Syst. 1995, 10, 948-956. [CrossRef]

23. Zhang, C.; Ke, D.; Sun, Y. Coordinated Supplementary Damping Control of DFIG and PSS to Suppress Inter-Area Oscillations with Optimally Controlled Plant Dynamics. IEEE Trans. Sustain. Energy 2018, 9, 780-791. [CrossRef]

(C) 2019 by the authors. Licensee MDPI, Basel, Switzerland. This article is an open access article distributed under the terms and conditions of the Creative Commons Attribution (CC BY) license (http://creativecommons.org/licenses/by/4.0/). 